\title{
The Operational Impact of Changing Collaboration Patterns on Retail Transport Service Providers
}

\author{
Adriana Florența PĂLĂȘAN ${ }^{1}$ \\ Daniel Dumitru BĂDIȚOIU ${ }^{2}$
}

\begin{abstract}
Like any other industry, transport faces major changes. This fact implies risks, but - at the same time - great opportunities for improvement and development. The triggers of change come from area of technology, customer's fast changing requirements and new industry actors that disrupt traditional business models. This study is aimed to achieve two of these aspects: the requirements of retail customers (contractual conditions agreed with the suppliers of transport for distribution to the stores) and the impact of the new technologies. This article focus is on the main conditions that develops new skills and competencies for service companies and remodels the processes according to new technologies.

The current analysis 'scope is to highlight the future trends of the relations between the customer and the carriers and the additional competences they will have to acquire on the Romanian market. The used research method was contract analysis and interviews with participating companies.
\end{abstract}

Keywords: contract, transportation, physical internet, patterns, rules,

JEL classification: L91; L92; M15; M21;

DOI: $10.24818 /$ RMCI.2019.1.88

\section{Introduction}

There is a wide debate on the future of logistics activity in general and on the transport activity. We talk about autonomous vehicles, electric motors, partnerships, customer expectations, complex competition, physical internet, impact of new startup entry. Internet transformed the flows of information everywhere. They where a clear border between the internet and the physical world. This one became blurred with the IoT (Internet of Things). Benoît Montreuil, professor of Material Handling and Distribution at the Georgia institute of Technology, developed the concept of the physical internet. It is a field of research and practice, which tries to optimize the supply chain. The Physical Internet aims to transport physical goods with the same performance as data flows around the web. Even if the internet became a part of our lives, connecting cars, light bulbs, watches and having a huge impact on our reality (ex: controlling the temperature in a room, increasing our security in the office and at home, etc.), the only one barrier between Internet and the physical world is the logistics. Purchasing an item online is fast easy and simple. Until the

${ }^{1}$ Adriana Florența Pălășan, e-mail: adriana@ loginet.ro

2 Daniel Dumitru Bădițoiu, e-mail: daniel.baditoiu@gmail.com 
point of delivery. Everyone had a black Friday experience. Waiting for days and weeks the parcel.

The world is demanding speed and efficiency. Performance is done by the slowest link in the chain. There are promoters of change and traditionalist companies or simply too pleased companies with current performance level to want new challenges. It is important the relationship between partners in the supply chain and its evolution in the local and international context.

Nowadays, transportation represent one of the most important tools to develop countries. It is the most important industry. A country became more and more developed if its transportation system is efficient and effective. In the aftermath of globalization, new markets and new customers, transport activities are becoming more and more diversified, the customers are becoming more demanding and the contractual conditions are becoming more sophisticated.

Over time some best-in-class transport and distribution models have emerged as best practices in some areas where the need of merchandise at a certain point of time required sustained efforts and rigorous attention for designing processes within companies as well as those at the border with suppliers and service providers. Depending on the economic context, the maturity of the market and the culture of the organizations, different transport models have been adopted with influences in the procurement and warehousing activity. There is always a compromise between the optimization of transport activities involving the transport of large volumes at optimal distances (so that the drivers' timetables can be respected) and the optimization of inventory costs, which are found both in the warehousing area and in the financing area (Mariotti, 2015).

Some of the main aspects to be considered in the analysis of the general framework needs to be highlighted:

\subsection{Retail in Romania and in the World}

Shops are closing as retail spending moves online. The US registered a record number of closings shops in 2017, with 6,885 shops already having shut their doors by December 1. In the 2016 New Digital Divide report, Deloitte found that digital interactions influence 56 cents of every dollar spent in bricks-andmortar stores, related to 36 cents, just three years prior. Furthermore, people who buy using different methods - including online, mobile and visits to a physical store - spend more than double than those who only shop at bricks-and-mortar stores, according to Deloitte's The Omnichannel Opportunity study. At international level, online companies like Amazon or big retailers such as Walmart give the trend of modernity. Europe, from a logistical perspective, has remained in the traditionalist area and although online acquisitions are spectacular, there have not been strong enough forces to change models.

In recent years, the Romanian market is dominated by the development of modern retail. After its extensive growth and the player's consolidation, modern retail occupies a dominant position both at the employee level and as a contribution 
to GDP. If at international level is registered a certain level of shops closing, at national level the expansion is increasing. An average of 300 stores open each year. Also on-line shopping, though in a shy manner for now, are beginning to weigh more and more in the percentage of total volumes. The consequence of these increases is represented by the growing demand for transport vehicles of both large tonnages and for local distribution also.

\subsection{The transport market and its challenges}

For the transport service provider to carry out its task properly, the transport process should be fast, flexible and accurate. The transport market does not differ greatly from one country to another, the difference being made by the infrastructure. But the impact is major: in countries with developed road infrastructure, the number of distribution centers is reduced, the distances for large capacity are increased and modern methods for optimization are used to share and cooperate, so delivery performances are notable.

At the same time technological developments lead to important changes in the relationships between partner companies, the integration of information systems aligns processes and often dictates contractual conditions.

International Key Accounts in Romania use in their entirely logistic platforms (one or more) where they centralize almost all the goods from suppliers and from where they distribution vehicles starts the deliveries to the store, being subject to tonnage restrictions. There are still a few networks that have not centralized more than $90 \%$ of the volume but also these ones have ongoing investments to align with market trends: for example, Metro, Auchan and Selgros. Their specificity is since being a cash-and-carry type, the volumes sold favored the pattern of stores deliveries. Today, these networks have added new formats and have increased the number of SKUs so it is necessary to restructure the transports and distribution platforms (Coyle, 2015).

Restrictions on tonnage and environmental protection are increasingly drastic and therefore, depending on the position of unloading locations, different gauge vehicles are required, with specialized equipment and most of the time cross-docking warehouses are required using transshipment to streamline activity and maintain a cost control.

Road infrastructure does not allow too much a centralization of operations and therefore the warehouse infrastructure serving retail stores is a well-established network. Some examples are Carrefour with 4 Distribution Centers, Kaufland with 2 (and preparing the $3^{\text {rd }}$ ), Lidl with 5 Distribution Centers, Profi with 5 Distribution Centers, Rewe with 3 Distribution Centers, Mega Image with 2 Distribution Centers, etc. Each network, depending on the location of the stores and their size, places a cross-docking warehousing in almost every town where small shops are present. Thus, the carriers for this distribution model have the activity divided into two main structures: Primary distribution from central warehouses to cross-docking and last mile distribution from cross-docking warehouses to stores. Thus, the 
transport capacities are different, the distances are different, the loading operations are different, and the driver's responsibility is different (McKinnon, 2017).

Almost all carriers have GPS tracking systems, but not all of them have data processing and reporting solutions in order to streamline their activity. Few are those who offer their customers real-time reviews on delivery status

\subsection{The common problem}

The major problem faced by the world market in this second decade of the century is the lack of qualified staff. The World Bank report, published in 2017, has expressly depicted the lack of truck drivers that are a major concern not only for Romania but also at European and World level.

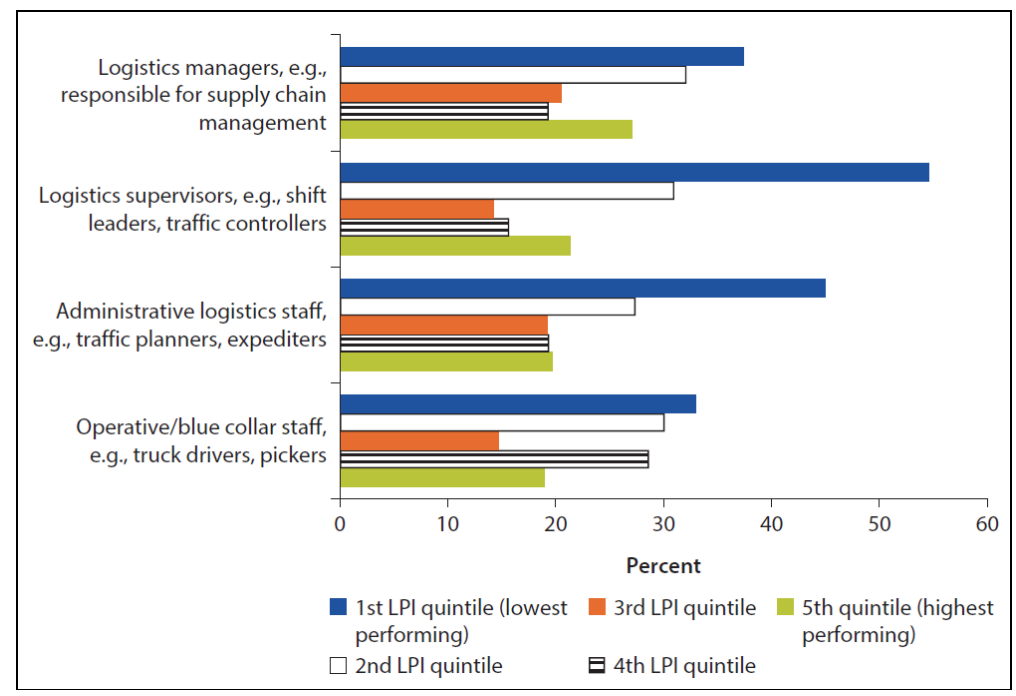

Figure 1: Availability of qualified personnel in the employee groups

Also, in the last decade, the phenomenon of migration that has helped a part of the developed countries (as in the case of the Western European countries), which depend on the drivers in Eastern Europe, those country also are now facing this lack of drivers, as is the case with Romania. The good part of these migrations is that they transfer some of the good practices, skills and competences from one country to another and from one industry to another. For example, for 2008, the European Union assessed the absence of TIR drivers for 74,480 people. A 2012 survey revealed that over $84 \%$ of European transport companies are facing lack of drivers. The study also shows that in over 10-15 years Germany will need about 150,000 drivers under the conditions that many of the existing drivers will retire (Forry, 2019).

Price Waterhouse Coopers logistics report (from 2016) "Shifting patterns the future of logistics industry" identifies several forces that can radically change the transport perspective in the following years. It is specified in the introduction of 
the study that "The trick to seeing the future [...] is knowing where to look for it". This statement represents a challenge for this study to see where to look for the future of supplier-client relationships.

\section{Description of the study}

The study was conducted in February 2019 on a representative sample of an international key accounts operating in Romania. Added to this were the national companies from Do-It-Yourself (DIY) and Electro that had a bigger growth than the international chains. The number of companies included in the study represents $50 \%$ of the total of each category.

The research method applied had two components: comparison of the contractual conditions with impact on the development of the carriers and the operating model and the interview conducted with the representatives of from the logistics departments that interact directly with the service providers and with the responsible providers. Contract models have evolved based on experience and none of them is a framework contract imposed at international level.

The structure of the study participants

Table 1

\begin{tabular}{|c|c|}
\hline Client type & Percent \\
\hline Retailer & $56 \%$ \\
\hline Electro & $23 \%$ \\
\hline DIY & $21 \%$ \\
\hline
\end{tabular}

They have contracts only with direct carriers with exception of two cases of logistics operators who have added themselves to the traditional carriers due to their personal affinity with transport departments representatives, recognized in the market for their professionalism (David, 2004).

None of the companies is using foreign companies for operations in Romania. This pattern is a national phenomenon, it does not matter the industry that needs the vehicles and the source from where they contract them, on the national territory goods are transported only with vehicles registered in Romania. It is rarely appearing the opportunity of a short-haul for a return of a vehicle coming back to the country of origin. The reason comes out from the tariffs applied in the transport market, which become unattractive due to lower limit of profitability.

The study was divided into several sections:

- Types of transport ordered and their related transportation contracts with general communication conditions

- Preliminary eligibility conditions

- Conditions according to vehicles statuses

- Operational issues

- Penalties and KPI's 


\section{Analysis of contractual conditions}

The customers want to rationalize their portfolio of transport service providers and seek to manage a limited number of suppliers.

\subsection{Transportation types}

In the case of primary transportation or large format retailers stores where access can be made to large tonnage vehicles (40 tons maximum authorized mass), carriers are dedicated, they have many vehicles, have financial strength and a high degree of standardization of operations. All of them have developed their business from a contract with a big client that has helped them to grow sustainably and develop their business.

In case of secondary transportation, this is operated with smaller vehicles: 6 tons, 7,5 tons, 10 tons, 12 tons maximum authorized weight. Contracts for these trips are generally awarded to small carriers who manage up to 7-10 vehicles but who do not have managerial resources to develop their business. This is the reason why there are numerous contracts in the last mile distribution and the rotation of the carriers is quite high. In addition, the contracting period is lower, in order to certify carriers' performance capabilities.

\subsection{Types of transport contracts}

Several categories of transport contracts are used in terms of complexity. The fastest one is the order contract; the easiest one is the simplest and the strongest one is the framework contract.

- Order contract - The order contract is the simplest model of contract between two parties. This type of contract is generally practiced on spot trips, on bid platforms or directly between expeditors (forwarders) and actual carriers. This contract model rarely meets Retailer's relationship with a transport service provider and is used in extreme emergencies. This contract contains only two pages: one with details about the order and on the back the general conditions to be respected.

- Simple transportation contract - A transport contract model with general, non-binding and unconditional clauses in terms of number of trips, volumes, destinations. Such contracts are used by DIY retailers and apply when many providers are used, in this case the price being the most relevant part. This contract has usually something like five pages and contains the classical clauses where the operational conditions generally lie with the Supplier's responsibilities. They might have just few appendixes or these may totally be omitted.

- Framework contract for transport services - This type of standard framework is the most common contract in the retail area, a contract that secures and guarantees the presence of an appropriate number of 
vehicles loaded. Usually this contract guarantees the volumes for a dedicated fleet with several vehicles covering the client's average and these contracts define the relationship between retailer and carrier in detail, developing the carriers and educating them to be competitive nationally and not only.

These contracts have detailed rules regarding the conditions that must be respected by the service providers that refers also to their own internal policies (staff hiring, staff training, taxes and fees, subcontracting rules of other companies, fuel purchase, drivers working hours, etc.). Several appendixes are attached, containing details of destinations references, tariff plan, KPI's, penalties, technical requirements, cold chain requirements, ADR, special transport, code of conduct, standard documents, mileage, guiding principle for suppliers, conventions on health and safety at work, reporting system, description of services.

\subsection{General communication conditions}

The established communication model is by email and phone. There are dedicated fleet/routes, where the carrier dispatcher works directly at the customer's location. In this case, with a $32 \%$ popularity in the retail transportation market, the communication process (including shipping orders) is direct.

Only one respondent has already set up an on-line communication system with transparent assignments of each trip to each service provider and can work in the same common environment with the customer to confirm the trip and truck details as well as time slot for loading, getting automatically any change alert. The loading status of each vehicle is visible on-line both for internal stakeholders and for the providers. The carrier's feedbacks are positive, observing in real-time what they cannot monitor on GPS out of vehicle's route.

\subsection{Preliminary eligibility conditions}

As opposed to other industries, the contracts used in retail industry, and especially those used in FMCG, contain clauses that enforce suppliers' ethical, responsible and sustainable conduct. $100 \%$ of the respondents ask for suppliers' official registration deed, transport licences and authorisations, insurance policies, technical inspection, liability insurances etc.

Over $67 \%$ of the respondents have extra requests, such as legally labour contracts for suppliers' employees, due taxes proof of payment, proving documents for drivers related to periodical exams and minimum 3 years' experience condition, drivers' permits for material handling and/or lifting equipment utilisation. Exposure to image damaging risks makes the retailers very cautious thus, they ask for extra guarantees from their suppliers.

94 Review of International Comparative Management

Volume 20, Issue 1, March 2019 


\subsection{Conditions for the state of the vehicles}

Within the regular transport, agreements there are clauses stating the general conditions required for the state of the vehicles. On the background of the precarious infrastructure as well as of the driver's severe shortage, the clients' conditions/requests are more detailed and, from this standpoint, the retailers have a sustainable policy that allows them to develop their suppliers' portfolio as well as their services quality at the same pace with their own business development. Thus, in addition to the standard conditions to be found in $100 \%$ of the contracts such as seamless technical state and lawfully sanitary conditions, in $23 \%$ of them we could find conditions regarding the fleet age: no older than 1-2 years form acquisition date and a renewal rate of maximum 7 years. This way they mitigate the incidents of downtime and incidents occurrence rate caused by technical state of the vehicles/fleet.

Another condition/clause found in these agreements is the one related to vehicles' branding. This is not a standard condition/clause, being found mostly in the cases of dedicated fleet. On the exclusively dedicated fleets, the clients ask for vehicles branding (logo, adds etc.) on their own expenses, targeting the increase of the company awareness by visual public exposure and they do not accept vehicles marked with their competitors' brandings (logo, adds etc).

If the fleets are not dedicated, the clients are branding only several of the vehicles and even can accept, upon prior notification and/or approval, trucks with competitors' branding. One of the clients using dedicated fleet required, by contract, special trucks' capacity by special internal dimensions of the trailers. Using Roll-cages, for securing and better mooring of transported goods during truck's running, the trailer's internal dimensions had to be changed.

\subsection{Included Services}

For $89 \%$ of the respondents, the driver needs multiple competencies to provide services seldomly required by other industries. Find below these types of requirements sorted by their occurrence frequency in transport agreements:

- Goods loading/unloading requirement - this requirement is one of the newest one used by the clients and led to important changes in drivers required set of competencies. Initiated at international level by Kaufland, it has been implemented in Romania too. Six months were needed for the carriers to comply with it. In order to do that they had to be trained and assessed for their ability in using material handling and lifting equipment, for their knowledge in recognizing packing types, goods types and their over-stacking capabilities.

- Supplementary services - one interesting requirement, found in the case of $22 \%$ of the respondents, is deliveries out of stores or hubs working hours (due to constraints such as heavy traffic, truck weight limit of the road etc.). This working set-up has an impact on both client and 
supplier. From client perspective, supplementary investments have been made for providing dedicated infrastructure where unloaded goods to be placed so their goods receipt could be processed in the following working hours cycle. By infrastructure, we mean floor area, high quality CCTV system, supplementary monitoring and locking systems. From the carrier's perspective, he assumes the keys (or other locking / unlocking systems), abiding the unloading place rules and procedures regarding opening doors and docks, unloading the goods, placing them in the dedicated area, and locking the back the doors and docks.

- Returns management - in the case of returns, $43 \%$ of the clients leaves the supplier the liberty to organize on its optimisation criteria the collection of the agreed returns (packing units, merchandise, equipment etc.). In addition, one of the respondents required also the delivery and return of documents to and from the stores.

\subsection{Operational requirements}

As per the prior chapter, they are listed below sorted by their occurrence frequency in transport agreements:

- Fuel floater - this clause has been found in all (100\%) analysed transport agreements. It offers the possibility of adjusting the transport rates in a transparent way with corrections derived from fuel price development. In $85 \%$ of the cases, the increment for triggering the rates adjustment is $+/-5 \%$. Another way of protecting and sustaining the carriers, found on $23 \%$ of the respondents, is managing the fuel by the client. It is a rare case in retail industry and usually is an approach aiming more to ensure the carrier's loyalty, on logistics services providers' case but especially on tractor trucks rental agreements. The amounts are transferred to the carriers by invoice. They do not have to deal with managing the fuel cards and contracts with fuel providers.

- Routes and unloading sequences - this condition is $80 \%$ of the cases set by the client. One of the reasons for that is the fact that transport services are not allocated to a single carrier and, usually, the client is significantly investing in routing and tracking software applications. Still, there are $20 \%$ of the cases when the client left this responsibility on carrier side giving them the opportunity to optimize their routing process. This model is used when there are software applications interfaced between client and carrier allowing the latter to collect data from the first's system (consumption at arrival) and has KPIs on savings and service level offered by replenishment of the stocks. This is a very specific case and is to be found where the carrier is also the logistics services provider for the client or where the processes are automatized, and the truck loadings are prioritized so the carriers to have a very good accuracy on scheduling. Seldomly is to be found on traditional 
international retailers being more common (and imported from) oil\& gas or conveniences industries.

- Overcame contracted volumes - this condition is found on only $50 \%$ of the contracts and all of them require a guarantee for a volume increase by $10 \%$. The retailers are usually in this case $(33 \%)$ and they do not apply penalties for carriers that could not cover the overflow. There are also cases where clients apply penalties in case of not covering the overflow, penalties stipulated in the contract.

- Management of the drivers - the drivers have to be professional and integer. This condition is found in all transport agreements and it is covered by several clauses such as abiding the AETR driving hours, replacing the drivers etc.

- Organizing aspects related to drivers' driving hours - to increase the utilisation rate, $34 \%$ of the respondents apply radical methods for their fleet. Several drivers could use the same vehicle. Tandem drivers cover long distances or in case of completing the legally allowed driving hours the driver(s) is (are) changed. For minimizing the times wasted by drivers between hotels and warehouses, $23 \%$ of the respondents are using living containers where the drivers get their legally required rest and sleep. This way, according to the respondents, the utilisation rate increased by an average of $60 \%$.

- Software applications interfacing and GPS real time data transparency we did not identify any case of such interface and any case of GPS real time data transparency neither. Thus, a lot of time is wasted with manually created reports and activity monitoring \& assessment.

\subsection{Penalties and Key Performance Indicators (KPIs)}

All contracts have penalties clauses. They are significantly different from one to another and they depend on the activities list and the imposed conditions regarding loading/unloading schedule. There are two main categories of penalties:

- Penalties due to non-conformities generated by transport suppliers - such as loading delays or failures due to wrong allocation, faulty truck allocation (technical state, wrong loading volume or payload capacity etc.), and delays in reporting or in invoicing extracts. These are regular applied penalties and their values are between 100-500 euros.

- Penalties due to errors or neglect of the drivers - these are a lot more numerous and they could be: wrong of failure in utilisation of safety equipment, loading/unloading errors, errors in using material handling and lifting equipment, parking errors, phone utilisation, cleaning rules violations, failing abiding the rules on loading/unloading/transporting of controlled temperature goods. About half of the respondents have these clauses in their transport agreements. 
Excepting the clauses for working safety and security and those related to temperature as safety of the goods condition, the reality revealed by interviews showed the fact that these penalties are applied only after repeatedly broken of the rules that shows real neglect or intentional attitude.

In addition, the interviews with the carriers revealed that less than $10 \%$ of them are monitoring their performance by their own systems other than the financial one and usually they are using the KPIs reports supplied by their clients.

\begin{tabular}{|c|c|c|c|}
\hline KPI & Definition & Target & Intervals \\
\hline Response Rate & $\begin{array}{l}\text { No of confirmed transport } \\
\text { orders / No of launched } \\
\text { transport orders }\end{array}$ & $98 \%$ & $\begin{array}{l}>98 \% \text { - OK } \\
98 \% \text { - } 90 \% \text { - max } 3 \text { cases followed by } \\
\text { monitoring and penalties } \\
<90 \% \text { - Closing the contract and penalties }\end{array}$ \\
\hline $\begin{array}{l}\text { On Time } \\
\text { Loading }\end{array}$ & $\begin{array}{l}\text { No of confirmed On Time } \\
\text { Loaded orders / No of } \\
\text { confirmed transport orders }\end{array}$ & $95 \%$ & $\begin{array}{l}>95 \%-\mathrm{OK} \\
95 \%-85 \%-\max 3 \text { cases followed by } \\
\text { monitoring and penalties } \\
<85 \% \text { - Closing the contract and penalties }\end{array}$ \\
\hline $\begin{array}{l}\text { On Time } \\
\text { Delivery }\end{array}$ & $\begin{array}{l}\text { No of On Time Delivered } \\
\text { orders / No of confirmed } \\
\text { transport orders }\end{array}$ & $90 \%$ & $\begin{array}{l}>90 \%-\mathrm{OK} \\
90 \%-85 \% \text { - max } 3 \text { cases followed by } \\
\text { monitoring and penalties } \\
<85 \% \text { - Closing the contract and penalties }\end{array}$ \\
\hline $\begin{array}{l}\text { Delivery } \\
\text { Accuracy }\end{array}$ & $\begin{array}{l}\text { No of intact delivered (so } \\
\text { non damaged and no } \\
\text { missing) boxes / No of } \\
\text { ordered or loaded boxes }\end{array}$ & $99,9 \%$ & $\begin{array}{l}>99,9 \%-\text { OK } \\
99,9 \% \text { - } 98 \% \text { - max } 3 \text { cases followed by } \\
\text { monitoring and penalties } \\
<98 \% \text { - Closing the contract and penalties }\end{array}$ \\
\hline $\begin{array}{l}\text { Order } \\
\text { Confirmation }\end{array}$ & $\begin{array}{l}\text { No of orders on time } \\
\text { confirmed (date \& hour) / } \\
\text { No of launched transport } \\
\text { orders }\end{array}$ & $95 \%$ & $\begin{array}{l}>95 \%-\mathrm{OK} \\
95 \%-80 \% \text { - max } 3 \text { cases followed by } \\
\text { monitoring and penalties } \\
<80 \% \text { - Closing the contract and penalties }\end{array}$ \\
\hline $\begin{array}{l}\text { Proof of } \\
\text { Delivery } \\
\text { Return }\end{array}$ & $\begin{array}{l}\text { No of Proof of Delivery } \\
\text { returned in time and in full } \\
\text { / No of issued Proof of } \\
\text { Delivery }\end{array}$ & $99.9 \%$ & $\begin{array}{l}>99,9 \%-\text { OK } \\
99,9 \% \text { - } 98 \% \text { - max } 3 \text { cases followed by } \\
\text { monitoring and penalties } \\
<98 \% \text { - Closing the contract and penalties }\end{array}$ \\
\hline $\begin{array}{l}\text { Invoicing } \\
\text { Accuracy }\end{array}$ & $\begin{array}{l}\text { No of correct and } \\
\text { complete invoices / No of } \\
\text { issued invoices }\end{array}$ & $99,9 \%$ & $\begin{array}{l}>99,9 \%-\text { OK } \\
99,9 \% \text { - } 98 \% \text { - max } 3 \text { cases followed by } \\
\text { monitoring and penalties } \\
<98 \% \text { - Closing the contract and penalties }\end{array}$ \\
\hline $\begin{array}{l}\text { Rules and } \\
\text { regulations in } \\
\text { health, safety, } \\
\text { labour, legal, } \\
\text { safe driving. }\end{array}$ & No of incidents & 0 & $\begin{array}{l}0 \text { - OK } \\
\text { 1-5/year - max } 3 \text { cases followed by } \\
\text { monitoring and penalties } \\
6-10 / \text { year - Penalties } \\
>10 / \text { year - Clients can close the contract } \\
\text { and apply closure penalties / charging } \\
\text { losses }\end{array}$ \\
\hline
\end{tabular}

Figure 2: 78\% of the audited contracts had explicit KPIs 


\section{Conclusions}

The Romania market is not prepared yet for a digital change. No contract clauses include some request for informatics systems, EDI or integration. Therefore, it is too soon to talk about Integration and Physical Internet. Even at international level, $90 \%$ of the experts underlines that in the near future, in transport and logistics industry is a great need of data analytics. The accent is on clauses designed to develop the transportation service provider as business, to help them to have a sustainable activity by imposing rules and less to think to changes.

There are major changes in driver position in supply chain. The driver is not anymore, a simple driver but is necessary to know and practice warehousing connected (or related) activities, goods and documents administration, and to have very good skills for transportation IT systems and equipment.

Transportation service provider is pushed to have more the role of problem solving and not an execution one: he is in charge to ensure transport capacity, drivers and service quality. There is also a trend in specialised transport service providers for different types of transportation (primary and secondary distribution). Based on knowledge, accumulated all over the year regarding the logistic market, we identified a correlation between transport service providers and specialization on primary and secondary distribution. Some of the carriers on the secondary distribution are distribution companies. Centralizing retailers' volumes of goods in distribution centres has led to a decrease in volumes over traditional distribution. The demand for smallsize vehicles for secondary distribution has come as a complement to making transport capacity more efficient. These distributors do not only offer transport services but have turned their local warehouses into last mile cross docking.

\section{References}

CIPS. 2016. Developing Contract in Purchasing and Supply manual. Profex Publishing Limited Coyle J, Novak, R. \& Gibson B, 2015, Transportation A global Supply Chain Perspective

David Frederick Ross, 2004. Distribution Planning and Control; Springer Science + Business Media Inc

Deloitte Touche Tohmatsu Limited, 2019, Global Powers of Retailing 2018 Transformative change, reinvigorated commerce [Online] Available at: https://www2.deloitte.com/content/dam/Deloitte/at/Documents [Accessed 15 March 2019]

Forry, N. Rahmat, A. 2019. The mediating role of technology and logistic integration in the relationship between supply chain capability and supply chain operational performance Growing science. 7(3). Pp. 553-566

Flash Global 2017 Physical internet, the next step for logistics. [Online] Available at: https://www.flash.global/en/blog/physical-internet-logistics/ [Accessed 17 March 2019]

Mariotti, I. 2015. Transport and Logistics in a globalisation world. Springer

McKinnon, A. Flöthmann, C. Hoberg, K \& Busch, C., 2017. Logistics. Competencies Skills, and Training a Global Overview. World Bank Study

PriceWaterhouseCoopers, 2016, Shifting Patterns - Future of the logistics industry [Online] Available at: https://www.pwc.com/sg/en/publications [Accessed 15 March 2019] 